\title{
ANÁLISE DO GRAU DE ERODIBLIDADE E PERDAS DE SOLO NA BACIA DO RIO CAPIÁ BASEADO EM SIG E SENSORIAMENTO REMOTO
}

\author{
Richarde Marques Silva ${ }^{1}$ \\ Fernanda Maria de L. Paiva ${ }^{2}$ \\ Celso Augusto Guimarães Santos ${ }^{3}$
}

Artigo recebido em 16/03/2009 e aceito para publicação em 01/09/2009.

\section{RESUMO}

A erosão dos solos é um dos mais sérios problemas ambientais que ocorrem em diversas partes do Brasil. A predição das perdas de solo em bacias sem informações de erosão é uma das tarefas mais desafiadoras em qualquer lugar do planeta, especialmente em países em desenvolvimento onde o monitoramento da produção de sedimentos é realizado em poucas bacias devido aos custos envolvidos ou devido à falta de pessoal treinado. Esse trabalho estudou a espacialização do grau de erodibilidade a partir das características pedológicas, e as perdas de solo, usando a Equação Universal de Perda de Solo (USLE) empregando técnicas de Sensoriamento Remoto e do Sistema de Informações Geográficas (SIG). O estudo foi realizado na Bacia do Rio Capiá, afluente do Rio São Francisco e localizada entre os Estados de Pernambuco e Alagoas, em uma área de $2.636 \mathrm{~km}^{2}$. Os dados utilizados neste trabalho incluíram levantamento de dados pluviométricos da bacia, mapas dos tipos de solos, altimetria, uso e ocupação do solo, e imagens de satélite. Os resultados mostraram que $24 \%$ da bacia apresenta alta suscetibilidade à erosão e $65 \%$ da área da bacia apresenta perda anual de solo entre 0 e 30 ton/ha/ano.

Palavras chave: GEOPROCESSAMENTO, EROSÃO, EUPS, BACIA CAPIÁ.

\section{EVALUATION OF SOIL ERODIBILITY AND SOIL LOSS IN CAPIÁ BASIN BASED ON GEOGRAPHICAL INFORMATION SYSTEM AND REMOTE SENSING}

\section{ABSTRACT}

Soil erosion is a serious and extensive environmental problem in many areas of Brazil. Prediction of soil loss in ungauged basins is one of the most challenging tasks anywhere and it is especially a very difficult one in developing countries where monitoring and continuous measurements of these quantities are carried out in very few basins either due to the involved costs or due to the lack of trained personnel. This study evaluates the erodibility degree spatialization through the pedologic characteristics, and the soil loss, using the Universal Soil Loss Equation (USLE) and employing Remote Sensing and Geographical Information Systems (GIS) techniques. The paper was accomplished in Capiá River Basin, which is a tributary of São Francisco river, located between the Pernambuco and Alagoas states, in an area of $2.636 \mathrm{~km}^{2}$. The data used in this paper to generate the USLE variables include the precipitation data, altimetry, soil, land use maps, and satellite images. The results showed that $24 \%$ of the basin presents high susceptibility to erosion and $65 \%$ of the basin area presents annual soil loss between 0 to $30 \mathrm{ton} / \mathrm{ha} / \mathrm{year}$, and that the remainder area of the basin presented soil loss with values around 40 up to 200 ton/ha/year.

Keywords: GEOPROCESSING, EROSION, USLE, CAPIÁ BASIN.

\footnotetext{
${ }^{1}$ Geógrafo, Mestre em Engenharia Urbana e Doutorando em Engenharia Civil pela UFPE. Endereço: Avenida Professor Morais Rego, s/n, Cidade Universitária. E-mail: richarde.marques@gmail.com.

${ }^{2}$ Universidade Federal de Pernambuco.

${ }^{3}$ Universidade Federal da Paraíba. Doutor em Recursos Hídricos/Ehime University
} 


\section{INTRODUÇÃO}

A erosão dos solos é um dos problemas ambientais mais importantes em todo mundo, sendo entendido como um fenômeno complexo resultante da interação de inúmeros fatores, compreendendo três fases distintas: desagregação, transporte e deposição. Os fatores que condicionam a erosão compreendem: (a) erosividade, (b) erodibilidade, (c) relevo, e (d) cobertura vegetal (SILVA et al., 2003).

As questões relacionadas à erosão têm aumentado consideravelmente nos últimos anos, especialmente em regiões semi-áridas de países como o Brasil, onde grande parte da população depende de atividades econômicas ligadas à agricultura. Existem várias regiões semi-áridas no planeta; entretanto, nenhuma destas possui a pluviosidade, a extensão e a densidade populacional do semi-árido do nordeste brasileiro.

A erosão causada pelas chuvas tem abrangência em especial nas áreas semiáridas, como no nordeste brasileiro, onde os totais pluviométricos se concentram em pequenos períodos do ano, o que agrava ainda mais a erosão. Esse processo tende a se acelerar, à medida que a cobertura vegetal é retirada para a produção agrícola, uma vez que os solos ficam desprotegidos e consequentemente, as chuvas incidem diretamente sobre a superfície do terreno
(SILVA et al., 2007b). Nas áreas sem cobertura vegetal e com solos mais susceptíveis à erosão, as perdas de solo são mais acentuadas. Assim, para estudar as regiões com mais probabilidade de erosão, nas últimas décadas estudos utilizando SIG, Geoprocessamento e Sensoriamento Remoto se constituem em importantes ferramentas para a avaliação da erosão dos solos (SILVA et al., 2007a).

Recentemente, diversas pesquisas foram realizadas para estimar a degradação do solo e os processos erosivos em bacias hidrográficas, a partir do uso das geotecnologias. Como exemplo de estudos usando essas técnicas, Lima et al. (1992) verificaram em área teste da Paraíba, a susceptibilidade natural e o risco de erosão por intermédio do uso de um SIG, desenvolvido especificamente para Sensoriamento Remoto e da Equação Universal da Perda de Solo, e mencionaram que a principal característica do estudo foi a possibilidade de se estimar, a partir de imagens de satélite, o risco de erosão em grandes áreas.

Jürgens \& Fander (1993) avaliaram a erosão do solo em uma pequena área, cujas informações sobre o uso e ocupação do solo foram determinadas por uma classificação multitemporal de duas imagens de satélite, e os fatores declividade e comprimento de vertente foram adquiridos por um modelo 
digital de elevação (MDE). Como resultado, correlacionaram as classes de uso do solo e sua contribuição à erosão, mostrando que solos com cultivo de vinhedos contribuíram mais para o processo de erosão do que as outras classes analisadas, e verificaram que solos profundos foram menos afetados pela erosão do que solos rasos.

Collado et al. (2002) analisaram dados de sensores remotos para monitorar 0 processo de desertificação em uma região árida da Argentina em dois períodos distintos, um chuvoso e um seco. Verificaram que mesmo em um ano considerado chuvoso para a região, não houve crescimento abundante da vegetação em comparação com o período de seca na região, devido ao fato do alto nível de degradação ambiental do solo. Já Huang \& Siegert (2006) utilizaram imagens obtidas por sensores orbitais para monitorar o processo de desertificação em uma região árida da China, usando imagens do SPOT VEGETATION com $1 \mathrm{~km}$ de resolução espacial para produzir um mapa da cobertura vegetal com ênfase especial na detecção de vegetação esparsa como um indicador de área de risco de desertificação. Concluíram que a melhor classificação para a identificação da vegetação esparsa foi obtida pela exploração sazonal da otimização do
Índice de Vegetação por Diferença Normalizada.

De Asis \& Omasa (2007) estimaram o percentual de vegetação para modelagem da erosão dos solos usando dados lineares por Spectral Mixture Analysis (SMA), em dados do sensor ETM do satélite Landsat 7. Os resultados mostraram que os valores estimados pelo modelo SMA foram extremamente satisfatórios quando comparados com dados observados em campo.

Portanto, a integração entre as geotecnologias e os processos ambientais vem sendo realizada com relevante sucesso em diversas partes do mundo e são de extrema importância para a espacialização, quantificação e gerenciamento dos recursos naturais. Assim, este estudo tem por objetivo analisar as características pedológicas e a susceptibilidade à erosão na Bacia do Rio Capiá, através da aplicação de técnicas de Sensoriamento Remoto e SIG.

\section{MATERIAL E MÉTODOS}

\section{Caracterização da Área de Estudo}

A Bacia do Rio Capiá está localizada na região semi-árida do nordeste do Brasil, entre os Estados de Pernambuco e Alagoas, mais precisamente dentro das coordenadas $9.020 .000 \mathrm{mN}, 8.920 .000 \mathrm{mN}, 620.000 \mathrm{mE}$ e $700.000 \mathrm{mE}$, e possui uma área de aproximadamente $2.636 \mathrm{~km}^{2}$ (Figura 1). 

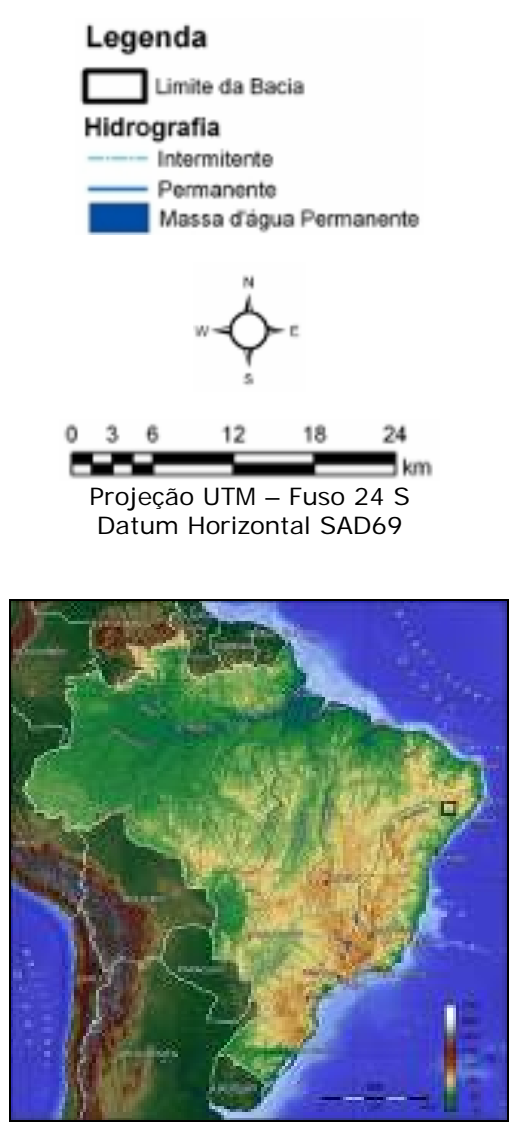

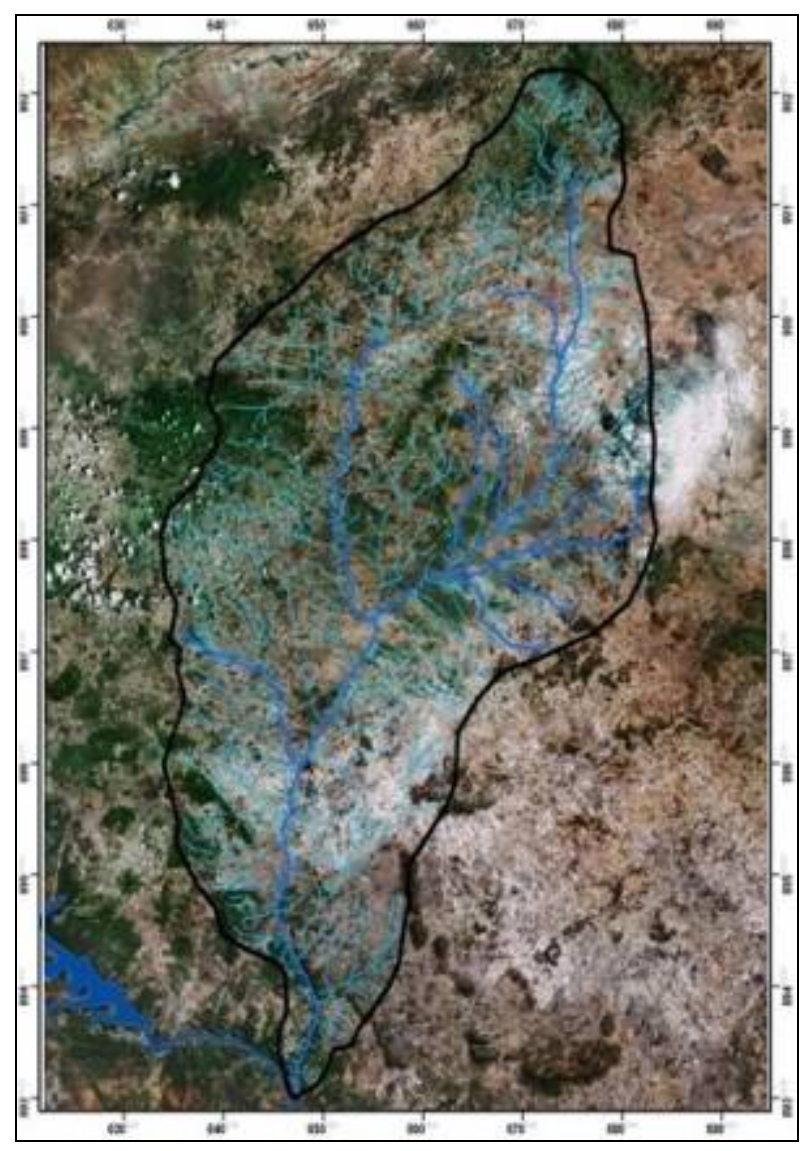

$6 x$

Figura 1 - Localização, drenagem e limite da bacia hidrográfica do Rio Capiá.

\section{Procedimentos Metodológicos}

A metodologia baseia-se em dois procedimentos: (a) análise das características pedológicas para obtenção do mapa da erodibilidade dos solos, e (b) determinação das perdas de solo utilizando o modelo USLE e geotecnologias. Para tanto, alguns procedimentos foram utilizados, como: produção do mapa de declividade, geração do mapa de uso e cobertura das terras, obtido a partir do processo de classificação das imagens orbitais, e aquisição do mapa de solos da região. Para tanto, foi adquirida uma cena de 19/08/2007 do sensor TM do satélite Landsat 5, com resolução espacial de
$30 \times 30$ m, e escolhida a composição colorida R5G4B3, uma vez que essa aplicação dos canais coloridos apresentou a maior identificação de elementos espaciais na imagem.

O georreferenciamento foi realizado utilizando o software ArcGIS, tomando-se como referência as cartas topográficas de Delmiro Gouveia (SC-24-X-C-III) e Poço da Cruz (SC-24-X-A-VI), ambas na escala de 1:100.000. Para o registro das imagens foi utilizado o polinômio de primeiro grau (Afim), com pontos de controle distribuídos de forma homogênea pela área mapeada no 
sistema de referência SAD69 e sistema de projeção UTM (fuso 24 S).

Para a construção da declividade, foi realizada a vetorização das curvas de nível e dos pontos cotados, em duas camadas, de forma manual em tela, a partir das cartas topográficas citadas anteriormente na estrutura matricial. Em seguida, converteuse cada vértice das curvas de nível em ponto, gerando assim uma nova camada de pontos, a qual posteriormente foi agrupada à camada dos pontos cotados, resultando assim uma única camada do tipo ponto com todas as informações altimétricas. Em seguida, foi utilizado o interpolador SPLINE, tipo Regularized, com peso 0,1, para gerar a grade regular. Optou-se pela grade regular por esta estrutura permitir uma melhor integração entre o MDE e as imagens orbitais.

O limite de pontos de entrada para cada ponto interpolado foi de 12 pontos, e o tamanho da célula de saída foi de $20 \mathrm{~m}$, visando compatibilizar com o tamanho do pixel da imagem do sensor TM do Landsat 5, utilizado na construção do MDE da bacia (Figura 2).

\subsection{Fatores do Modelo de Perdas de Solo}

\section{USLE}

O modelo de perdas de solo utilizado foi a USLE (Universal Soil Loss Equation). A USLE (WISCHMEIER \& SMITH, 1978)

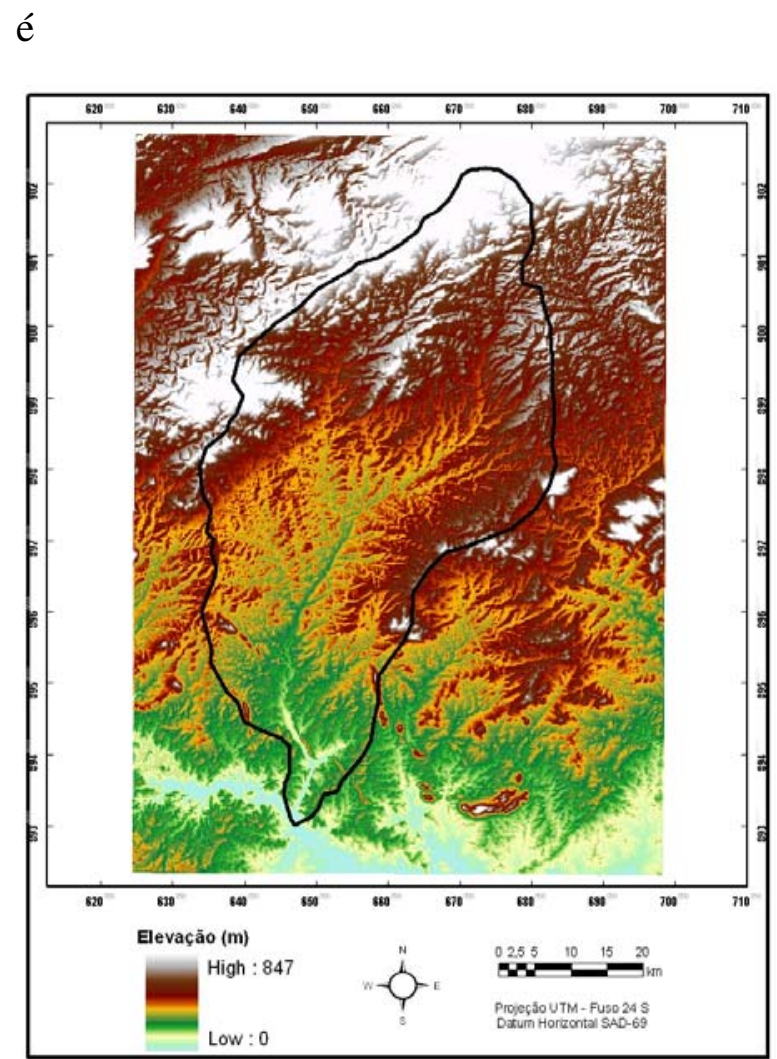

Figura 2 - MDE com limite e hidrografia da Bacia do Rio Capiá.

um modelo de base empírica que calcula a erosão do solo através de valores determinados por índices que representam os principais fatores, i.e., chuva, erodibilidade, topografia e uso do solo. A USLE pode ser utilizada na identificação de riscos de degradação de solos em microbacias, desde que adaptado às condições de estudo. A USLE é expressa pela Equação (1):

$A=R \times K \times L S \times C \times P$

sendo:

$A=$ unidade de perda de solo por área no tempo (t/ha); 
$R=$ fator de chuva ou índice de erosão pela chuva (MJ/ha.mm/ha);

$K$ = fator de erodibilidade do solo, isto é, a intensidade de erosão por unidade de índice de erosão da chuva (t.ha.h/ha.MJ.mm);

$L S=$ fator conjunto de comprimento de rampa e grau de declividade;

$C=$ fator uso e manejo, isto é, a relação entre perdas de solo de um terreno cultivado em dadas condições e as perdas correspondentes de um terreno mantido continuamente descoberto;

$P=$ fator de prática conservacionista, entendido como a relação entre as perdas do solo de um terreno cultivado com determinada prática.

$O$ fator $R$ da USLE utilizado no trabalho foi obtido segundo SUDENE (1985), que calculou a erosividade para toda a região Nordeste do Brasil, a partir da Equação (2) de Lombardi Neto e Moldenhauer (1980).

$E I_{\text {mensal }}=89,823\left(P_{m}{ }^{2} / P_{a}\right)^{0,759}$

onde $E I_{\text {mensal }}$ é média mensal do índice de erosão (MJ.mm/h·ha), para o mês considerado, $P_{m}$ é a precipitação mensal (mm) do mês considerado, e $P_{a}$ é a precipitação média anual (mm).
$\bar{P}=\frac{\sum_{i=1}^{n} A_{i} P_{i}}{A_{T}}$

no qual $\bar{P}$ é a precipitação média na bacia (mm), $A_{i}$ é a área do respectivo polígono, dentro da bacia $\left(\mathrm{km}^{2}\right), P_{i}$ é a precipitação no posto $i(\mathrm{~mm})$, e $A_{T}$ é a área total da bacia.

A Figura 3 mostra a distribuição sazonal do fator de erosividade $(R)$ para a bacia em estudo, obtido a partir da interpolação dos valores do fator $R$ para as quatro estações pluviométricas utilizadas. Os valores da erosividade na Bacia do Rio Capiá variaram de 285 à $615 \mathrm{MJ} \cdot \mathrm{mm} / \mathrm{h} \cdot \mathrm{h} a$, com valor médio de $435 \mathrm{MJ} \cdot \mathrm{mm} / \mathrm{h} \cdot \mathrm{ha}$. Os maiores índices de erosividade encontram-se na parte centro-oeste da bacia, e os menores na região sul da bacia (no exutório), onde predomina áreas de cultivo e solo exposto. 


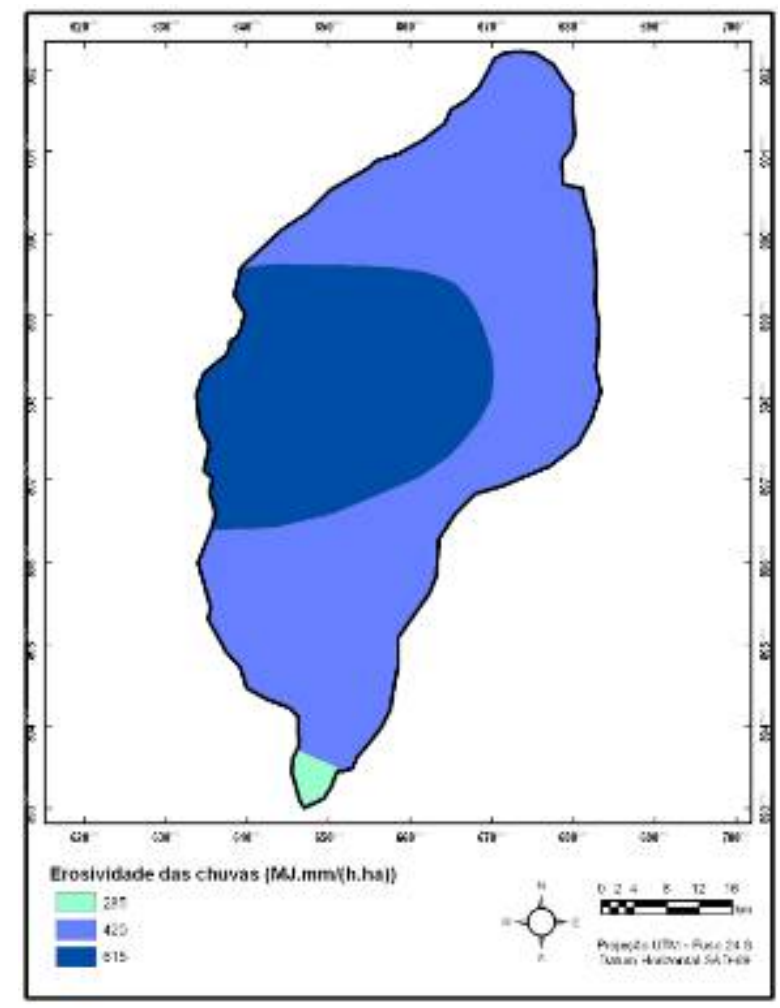

Figura 3 - Erosividade calculada para a Bacia do Rio Capiá.

De acordo com as classes de interpretação para índices de erosividade proposto por Carvalho (1994), este valor médio da erosividade na Bacia do Rio Capiá é considerado como médio (Tabela 1).

Tabela 1. Classes de interpretação para índices de erosividade

\begin{tabular}{cc}
\hline $\begin{array}{c}\text { Intervalo } \\
\text { (MJ·mm/h·ha) }\end{array}$ & $\begin{array}{c}\text { Interpretação } \\
\text { da Erosividade }\end{array}$ \\
\hline$R<250$ & Baixa \\
$250>R<500$ & Média \\
$500>R<750$ & Média a Forte \\
$750>R<1000$ & Forte \\
$R>1000$ & Muito Forte \\
\hline
\end{tabular}

A distribuição espacial do fator $K$ está diretamente relacionada à variabilidade dos solos, tendo em vista que a erodibilidade é

uma propriedade inerente ao tipo de solo. A metodologia utilizada para a obtenção do fator $K$, além de seu alto custo, demanda muito tempo até que sejam obtidos valores definitivos sobre unidades específicas dos solos. Apesar desta limitação, vários pesquisadores vêm realizando experimentos para determinar o fator de erodibilidade dos solos. Dentro desse contexto, para os solos da região Nordeste do Brasil destacam-se os trabalhos de Margolis et al. (1985), Távora et al. (1985), Albuquerque et al. (2002) e Farinasso et al. (2006).

Foram compilados valores para o fator de erodibilidade de alguns solos do Brasil, disponíveis na literatura para unidades pedológicas similares às da área em estudo, onde os valores foram adquiridos em experimentos de campo. Os valores encontrados foram associados aos solos da área em estudo em função de suas características físicas. Para a Bacia do Rio Capiá, os valores da erodibilidade dos solos foram obtidos a partir dos obtidos nos estudos citados anteriormente. Os valores foram associados em mapas de solo na escala de 1:100.000, baseados em SUDENE (1987) e EMBRAPA (2001). Os valores da erodibilidade dos solos existentes na Bacia do Rio Capiá estão apresentados na Tabela 2. 
Os mapas foram georreferenciados e os tipos de solos vetorizados no software ArcGIS. Em seguida, foi associado para cada tipo de solo o valor da erodibilidade baseado em Albuquerque et al. (2002) e Farinasso et al. (2006). Por meio do mapa de tipos de solos, observa-se que predominam na bacia os solos do tipo Neossolos Regolítico e Luvissolos (Figura 4). A Figura 4 mostra ainda a espacialização da erodibilidade dos solos na Bacia do Rio Capiá.

Tabela 2. Valores do fator $K$ para os solos na Bacia do Rio Capiá

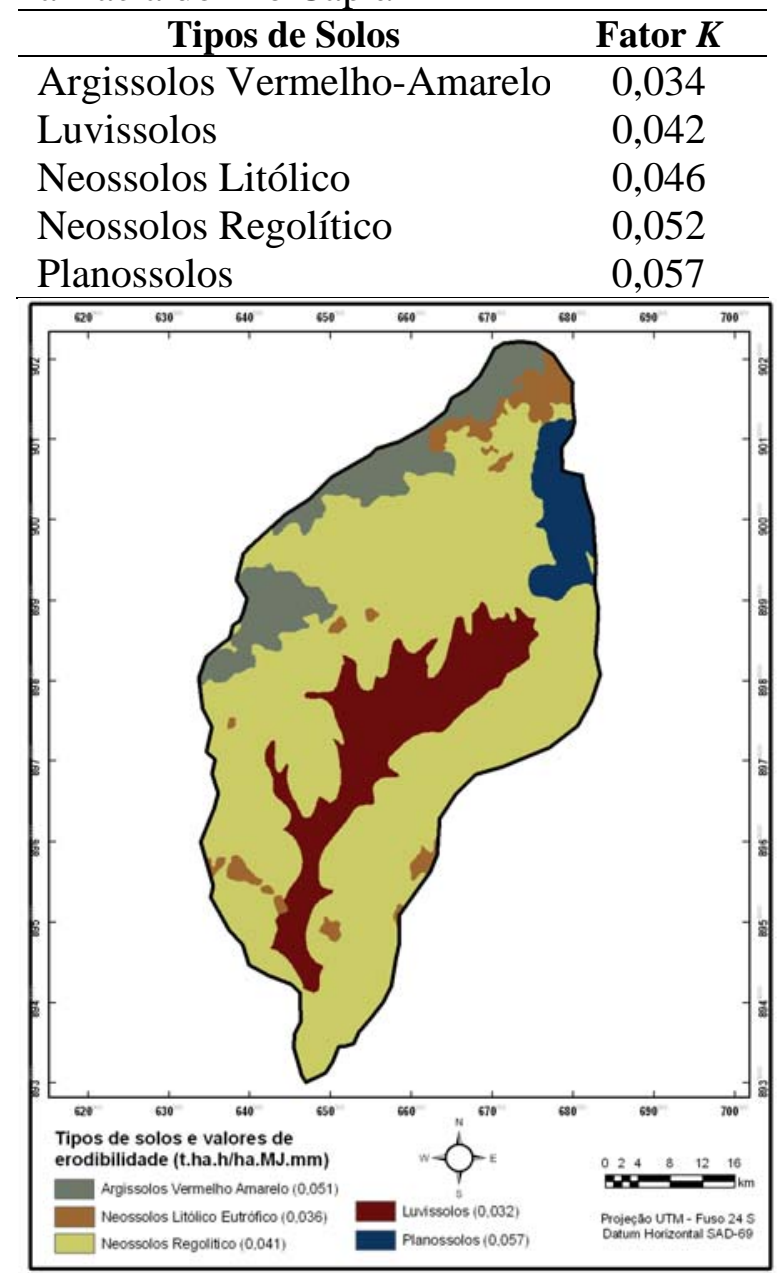

Figura 4 - Erodibilidade dos solos na Bacia do Rio Capiá.

Existem diversos métodos para a determinação do fator topográfico e do comprimento de rampa (LS) (Williams e Berndt, 1976; Moore \& Burch, 1986; Desmet e Govers, 1996; Kinnell, 2007). Neste trabalho, utilizou-se o modelo proposto por Moore \& Burch (1986) e Engel e Mohtar (2006), como mostrado na Equação (4):

$$
L S=\left(\frac{V}{22,13}\right)^{0,4}\left(\frac{\sin \theta}{0,0896}\right)^{1,3}
$$

sendo $V$ a acumulação de fluxo multiplicada pelo tamanho da célula e $\theta$ o ângulo da declividade em graus. A Figura 5 mostra a espacialização do fator $L S$ para a Bacia do Rio Capiá. 


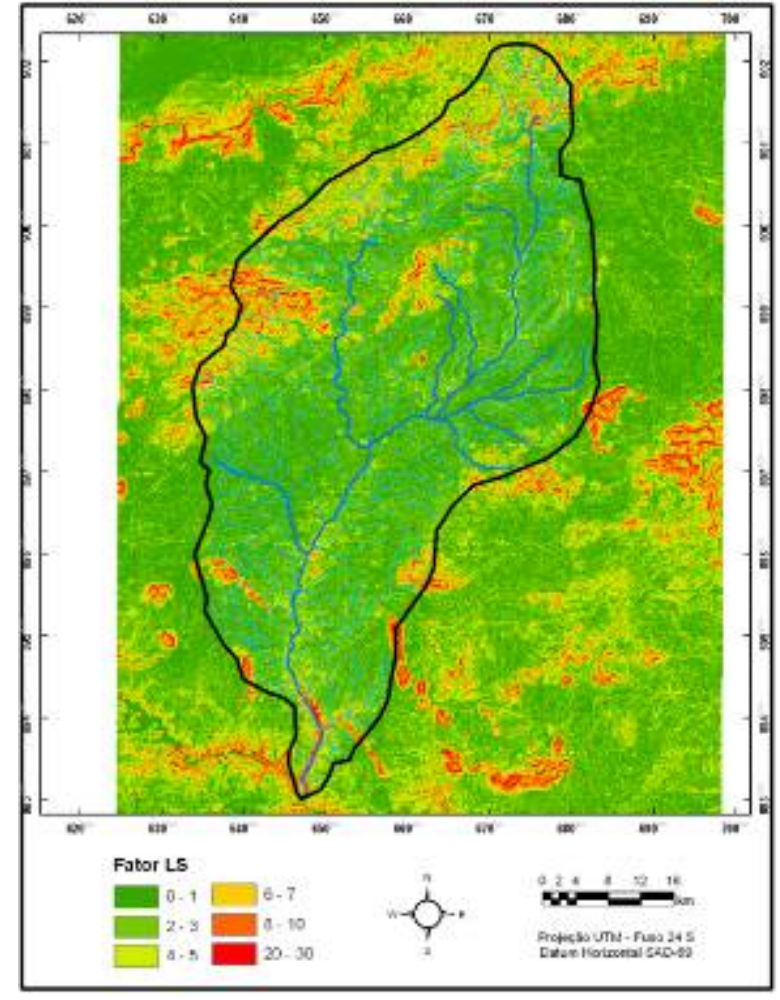

Figura 5 - Espacialização do fator $L S$ para da Bacia do Rio Capiá.

Os fatores de uso e ocupação do solo e práticas conservacionistas (fatores $C$ e $P$ ) foram obtidos a partir das imagens orbitais do sensor TM do satélite Landsat 5, da órbita 214/ponto 65. Foram identificadas na imagem amostras das seguintes classes: (a) água, (b) ocupação urbana, (c) vegetação, (d) cultivos; (e) caatinga; (f) solo exposto; e (g) afloramentos rochosos. A bacia foi então classificada no software ENVI pelo sistema de classificação supervisionada, usando o método de máxima verossimilhança, com limiar igual a 0,1. As Figuras 6 e 7 mostram os usos e manejos do solo e as práticas conservacionistas identificadas na Bacia do Rio Capiá.

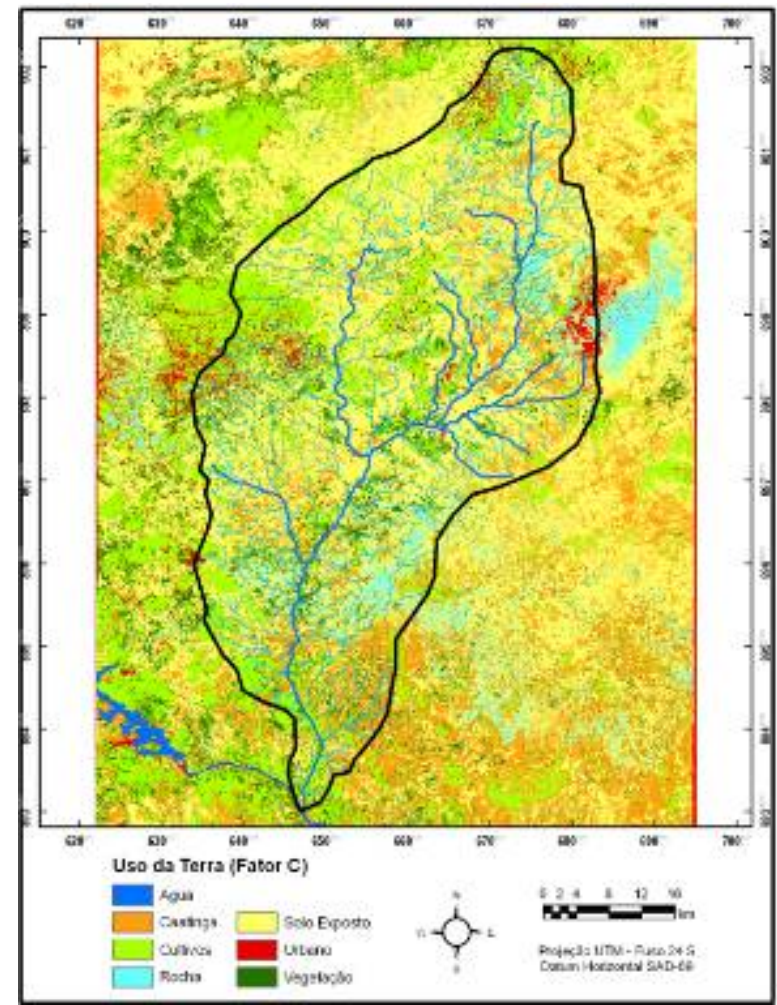

Figura 6 - Espacialização do fator de uso e manejo da terra na Bacia do Rio Capiá.

Após a classificação da imagem orbital, o arquivo foi importado para ambiente SIG, onde foram atribuídos os valores dos fatores $C$ e $P$ para os elementos classificados, de acordo com os sugeridos por Bertoni e Lombardi Neto (1985). Para as áreas não cultivadas, adotou-se o valor máximo 1,0 e para as áreas com agricultura foi usado o valor de 0,5. As Tabelas 3 e 4 apresentam os valores dos fatores $C$ e $P$ encontrados na bacia, respectivamente.

Devido ao fato da área de estudo se localizar em área semi-árida, há a predominância de vegetação do tipo caatinga e grande presença de solo exposto, como visualizado na Figura 6. 


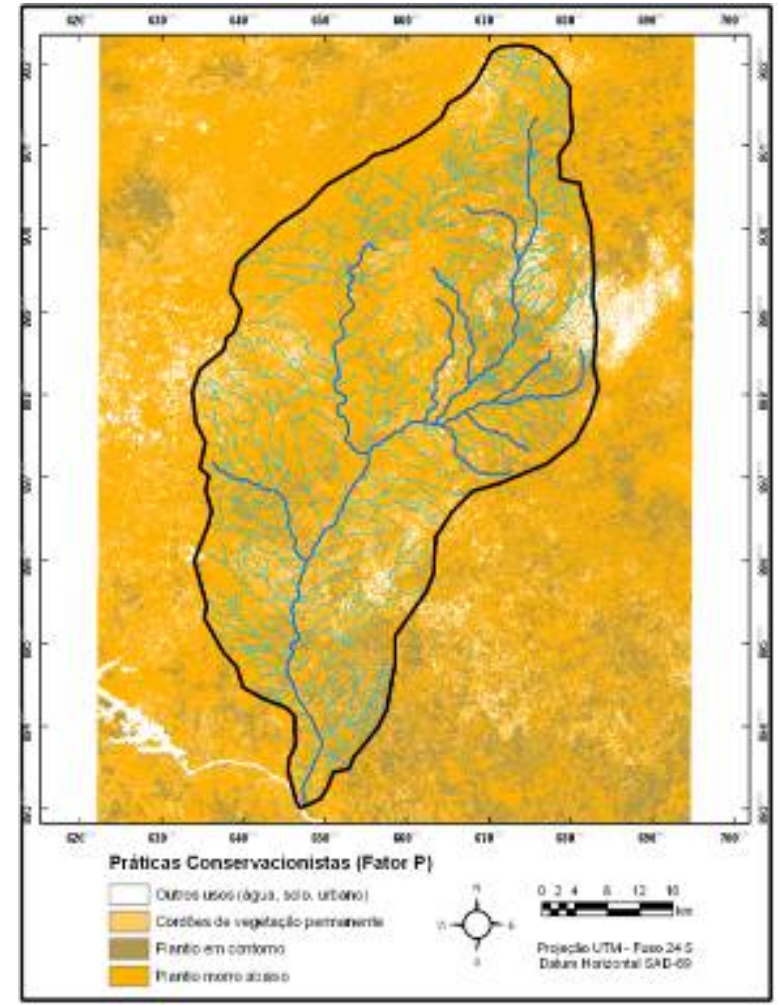

Figura 7 - Espacialização do fator de práticas conservacionistas na Bacia do Rio Capiá.

Tabela 3. Valores do fator $C$ relacionados às categorias de uso da terra

\begin{tabular}{lc}
\hline \multicolumn{1}{c}{ Uso da Terra } & Fator $\boldsymbol{C}$ \\
\hline Água & 0,000000 \\
Caatinga & 0,017800 \\
Cultivos & 0,542900 \\
Rocha & 0,000001 \\
Solo exposto & 0,100000 \\
Urbano & 0,000050 \\
Vegetação com boa cobertura & 0,000100 \\
\hline
\end{tabular}

Sobre a influência do tipo da cobertura vegetal sobre a erosão no semi-árido, Santos et al. (2000) ressaltam que as modificações na cobertura vegetal nas bacias hidrográficas produzem os mais variados impactos no meio ambiente, e o escoamento superficial é um dos primeiros fatores a serem alterados quando a cobertura vegetal da bacia é modificada, acarretando assim, no aumento da produção de sedimentos.

Tabela 4. Valores do fator $P$ para algumas práticas de conservação

\begin{tabular}{lc}
\multicolumn{1}{c}{ Práticas de Conservação } & Fator $\boldsymbol{P}$ \\
\hline Plantio morro abaixo & 1,00 \\
Plantio em contorno & 0,20 \\
Cordões de vegetação permanente & 0,09 \\
Outros usos (água, solo, urbano) & 0,00 \\
\hline
\end{tabular}

\subsection{Níveis de Susceptibilidade à Erosão}

Para realizar a identificação das características das classes pedológicas dos tipos de solo, e consequentemente, o grau de erodibilidade do solo, foi realizado o seguinte procedimento: (a) levantamento detalhado dos tipos de solo existentes na área de estudo, (b) análise e descrição das características positivas e negativas para cada tipo de solo quanto à sua susceptibilidade à erosão, e (c) determinação do nível do grau de erodibilidade dos solos, atribuindo para cada tipo de solo um peso (baixo, médio e alto), segundo o nível de susceptibilidade à erosão dos solos:

(a) Baixo: solos que possuem ótima resistência aos processos erosivos.

(b) Médio: solos que possuem média resistência à erosão.

(c) Alto: nesse nível foi levado em consideração o critério de maior 
susceptibilidade à erosão, isto é, solos que possuem grande erodibilidade.

\section{RESULTADOS E DISCUSSÃO}

A Tabela 5 apresenta a área abrangida, segundo os tipos de solo na Bacia do Rio Capiá. No que tange o grau de erodibilidade dos solos, percebe-se que $72 \%$ dos solos apresentam alta susceptibilidade à erosão (Nível Alto), devido ao fato de grande parte da bacia se constituir de Neossolos Regolítico, que se caracterizam por serem áreas potencialmente críticas, com alta suscetibilidade à erosão, e bastante susceptíveis a fenômenos geológicos, como movimentos em massa. Estes tipos de solos apresentam camada superficial muito rasa e ocorrem em áreas íngremes, sendo a velocidade de remoção dos solos acentuada, não permanecendo nenhum solo, ficando a rocha exposta e o material do solo é escoado para as partes mais baixas e côncavas assim que ocorre o desmatamento.

Ainda de acordo com os resultados obtidos, $4 \%$ apresentam condições regulares dependo das condições hidroclimáticas da região (Nível Médio) e 24\% apresentam grande susceptibilidade à erosão (Nível Baixo). A Figura 8 mostra a espacialização dos níveis de susceptibilidade à erosão dos solos obtida para a Bacia do Rio Capiá.

Tabela 5. Área abrangida e tipologia dos solos quanto à sua susceptibilidade à erosão.

\begin{tabular}{lccc}
\hline \multicolumn{1}{c}{ Tipo de solo } & Área $\left(\mathbf{k m}^{\mathbf{2}}\right)$ & Percentual na bacia (\%) & Nível \\
\hline Argissolos & 257,46 & 9,77 & Baixo \\
Luvissolos & 377,56 & 14,32 & Baixo \\
Planossolos & 116,36 & 4,41 & Médio \\
Neossolos Litólico & 141,47 & 5,37 & Alto \\
Neossolos Regolítico & $1.743,61$ & 66,13 & Alto \\
TOTAL & $\mathbf{2 . 6 3 6 , 4 6}$ & $\mathbf{1 0 0 , 0}$ & - \\
\hline
\end{tabular}




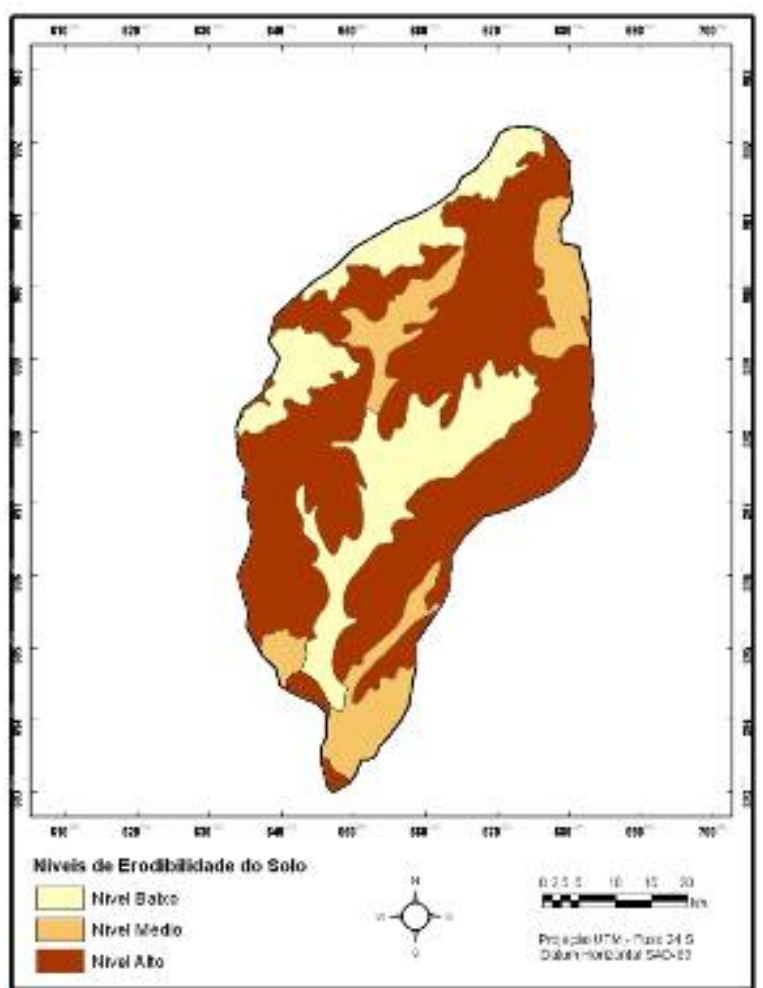

Figura 8 - Mapa dos níveis de susceptibilidade à erosão do solo da Bacia do Rio Capiá.

Percebe-se que 60\% da área da bacia são constituídas por solos com alta erodibilidade, $15 \%$ com solos de média susceptibilidade à erosão e apenas 25\% de solos considerados como de baixa erodibilidade.

A Figura 9 apresenta a espacialização das perdas de solo na Bacia do Rio Capiá, obtidos pelo cálculo da USLE em ambiente SIG. Para analisar as perdas de solo na bacia, Carvalho (1994) define seis classes para análise de perdas de solo em bacias hidrográficas (t/ha/ano): (a) $<15=$ nula a pequena, (b) 15-50 = moderada, (c) 50-120
= média a forte, (d) 120-200 = forte, e (e) > $200=$ muito forte .

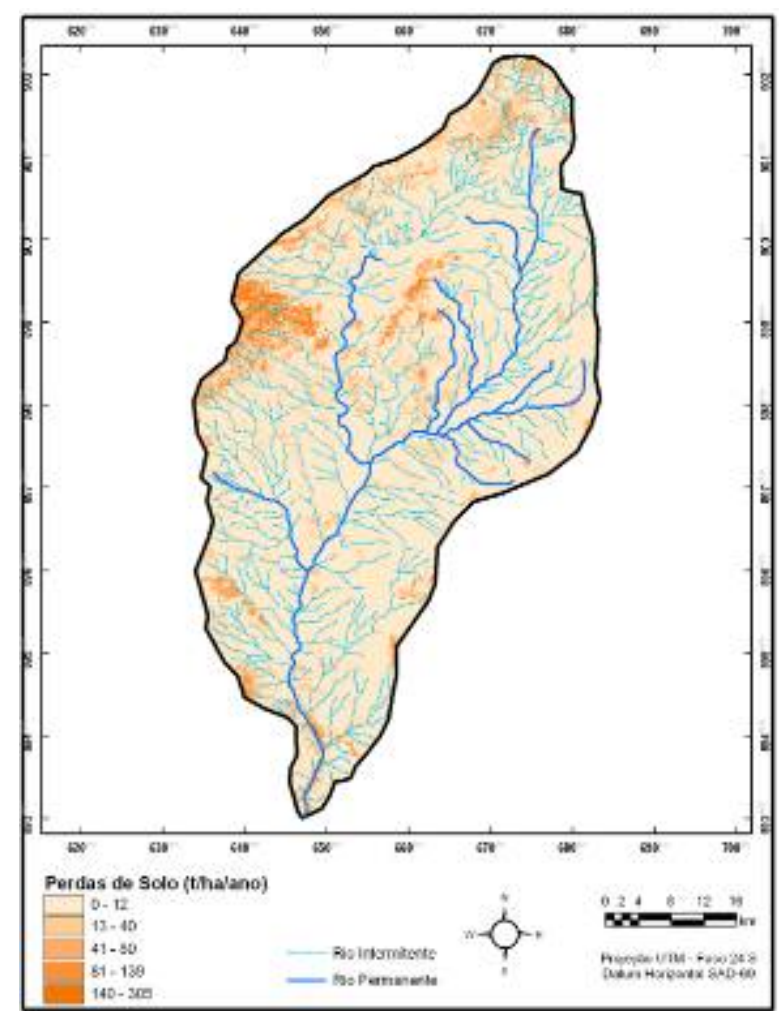

Figura 9 - Estimativa das perdas de solo na Bacia do Rio Capiá.

Analisando os dados, constata-se que grande parte da bacia apresenta um potencial de perdas de solo considerado como nulo a pequeno, e que uma pequena porção do noroeste e na parte central da mesma apresentaram um potencial assumido de médio a muito forte.

\section{CONCLUSÕES}

- Os resultados mostraram que $60 \%$ da bacia são constituídos por solos que apresentam alta susceptibilidade à erosão (Nível Alto). 
- As perdas de solo calculadas pelo modelo USLE mostraram que 65\% da área da bacia apresentam perda anual de solo entre 0 e 40 t/ha/ano, e que o restante da área da bacia apresentou perdas de solo com valores em torno entre 40 e $200 \mathrm{t} / \mathrm{ha} / \mathrm{ano}$, mostrando que a bacia possui perda de solo que pode ser considerada como moderada.

- As regiões com presença dos solos Luvissolos e Argissolos VermelhoAmarelo necessitam de maiores estudos para averiguação da existência de processos erosivos na bacia.

\section{AGRADECIMENTOS}

Os autores agradecem à FACEPE Fundação de Amparo à Ciência e Tecnologia do Estado de Pernambuco, pelas bolsas de Doutorado e ao CNPq e a FINEP pelo auxílio financeiro para a realização desta pesquisa.

\section{REFERÊNCIAS}

Albuquerque, A. W.; Moura Filho, G.; Santos, J. R.; Costa, J. P. V.; Souza, J. L. Determinação de fatores da equação universal de perda de solo nas condições de Sumé, PB. Revista Brasileira de Engenharia Agrícola e Ambiental, v.9, n.2, p.180-188, 2005.

Bertoni, J.; Lombardi Neto, F. Conservação do Solo. São Paulo: Ícone, 1985. 392 p.
Bertoni, J.; Lombardi Neto, F.; Benatti Junior, R. Equação de perdas de solo. Boletim Técnico n. 21, Campinas: IAC, 1975. 25p.

Carvalho, N. O. Hidrossedimentologia Prática. CPRM, Rio de Janeiro, 1994.

Collado, A. D.; Chuvieco, E.; Camarasa, A. Satellite remote sensing analysis to monitor desertification processes in the crop-rangeland boundary of Argentina. Journal of Arid Environments, v.52, p.121133, 2002.

De Asis, A. M.; Omasa, K. Estimation of vegetation parameter for modeling soil erosion using linear Spectral Mixture Analysis of Landsat ETM data. Journal of Photogrammetry \& Remote Sensing, v.62, p.309-324, 2007.

Desmet, P. J. J.; Govers, G. A GIS procedure for automatically calculating the USLE LS factor on topographically complex landscape units. Journal of Soil and Water Conservation, v. 51, n. 5, p. 427433, 1996.

EMBRAPA (Empresa Brasileira de Pesquisa Agropecuária). Zoneamento Agroecológico do Estado de Pernambuco. Recife: Embrapa Solos - Unidade de Execução de Pesquisa e Desenvolvimento - UEP Recife; Governo do Estado de Pernambuco (Secretaria de Produção Rural e Reforma Agrária), 2001. CD-ROM - (Embrapa Solos. Documentos; n. 35).

Engel, B.; Mohtar, R. Estimating soil erosion using RUSLE and the ArcView GIS. Acesso em: 01 de março de 2007. http://pasture.ecn.purdue.edu/ abe526/resou rces1/workshop/gisrusle2.doc. Acesso em: 06/05/2008. 
Farinasso, M.; Carvalho Júnior, O. A.; Guimarães, R. F.; Gomes, R. A. T.; Ramos, V. M. Avaliação qualitativa do potencial de erosão laminar em grandes áreas por meio da EUPS - Equação Universal de Perdas de Solos utilizando novas metodologias em SIG para os cálculos dos seus fatores na região do Alto Parnaíba PI-MA. Revista Brasileira de Geomorfologia, v. 7, n. 2, p. 73-85, 2006.

Huang, S.; Siegert, F. Land cover classification optimized to detect areas at risk of desertification in North China based on SPOT VEGETATION imagery. Journal of Arid Environments. v.67, p.308327, 2006.

Jürgens, C.; Fander, M. Soil erosion assessment and simulation by means of SGEOS and ancillary digital data. International Journal of Remote Sensing, v. 14, n.15, pp. 2847-2855, 1993.

Kinnell, P. I. A. Alternative approaches for determining the USLE-M slope length factor for grid cells. Soil Science Society of America Journal, n. 69, p. 674-680, 2005.

Lima, E. R. V.; Kux, H. J. H.; Sausen, T. M. Sistema de informações geográficas e técnicas de sensoriamento remoto na elaboração de mapa de riscos de erosão no sertão da Paraíba. Revista Brasileira de Ciência do Solo, v.16, n.2, p.257-263, 1992.

Lombardi Neto, F.; Moldenhauer, W. C. Erosividade da chuva: sua distribuição e relação com perdas de solo em Campinas, SP. Anais do III Encontro Nacional de Pesquisa Sobre Conservação do Solo, p. 1325, 1980.

Margolis, E.; Silva, A. B.; Jacques, F. Determinação dos fatores da equação universal de perdas de solo para as condições de Caruaru (PE). Revista
Brasileira de Ciência do Solo, v. 9, n. 1, p. 165-169, 1985.

Moore, I. D.; Burch, G. Physical basis of the length-slope factor in the Universal Soil Loss Equation. Soil Science Society of America Journal, n. 50, p. 1294-1298, 1986.

Santos, C. A. G.; Suzuki, K.; Watanabe, M.; Srinivasan, V. S. Influência do tipo da cobertura vegetal sobre a erosão no semiárido paraibano. Revista Brasileira de Engenharia Agrícola e Ambiental, v. 4, n. 1, p. 92-96, 2000.

Silva, A. M.; Schulz, H. E.; Camargo, P. B. Erosão e hidrossedimentologia em bacias hidrográficas. São Carlos: Rima, 2003, 140p.

Silva, R. M., Santos, C. A. G.; Silva, L. P. Evaluation of soil loss in Guaraíra Basin by GIS and Remote Sensing based model. Journal of Urban and Environmental Engineering, v.1, n. 2, p.44-52, 2007a. doi: 10.4090/juee.2007.v1n2.044052.

Silva, R. M., Santos, C. A. G.; Silva, L. P., Silva, J. F. C. B. C. Avaliação espacial e temporal de perdas de solo usando o Sistema de Informações Geográficas (SIG). OKARA: Geografia em debate, v.1, n. 2, p.24-37, 2007b.

SUDENE (Superintendência do Desenvolvimento do Nordeste). Mapa de erosividade do Nordeste. Recife: SUDENE, 1985, 50 p.

SUDENE (Superintendência do Desenvolvimento do Nordeste). Levantamento exploratórioreconhecimento dos solos do Estado de Alagoas. Recife: Embrapa Solos/UEP, 1987.

Távora, M. R. P.; Silva, J. R. C.; Moreira, E. G. S. Erodibilidade de dois solos da região de Ibiapaba, Estado do Ceará. Revista 
Brasileira de Ciência do Solo, v. 9, n. 1, p. 59-62, 1985.

Williams, J. R.; Berndt, H. D. Determining the universal soil loss equation's lengthslope factor for watersheds. Proceedings of the National Soil Erosion Conference, West Lafayette, 1976.

Wischmeier, W. H.; Smith, D. D. Predicting rainfall erosion losses. Guide to Conservation Farming. US Department of Agriculture Handbook, n.537, 1978, 58p. 